\title{
Louis Dumont: Verdensforsagelse, hierarki og renhed
}

\author{
MIKAEL AKTOR, SYDDANSK UNIVERSITET
}

ENGLISH ABSTRACT: This brief article reviews two main contributions by the French sociologist Louis Dumont, his essay "World Renunciation in Indian Religions" and his major work on the Indian caste system, Homo Hierarchicus. Some of the critique of Dumont's ideas about renunciation, hierarchy and purity is discussed with special focus on three points: (1) The creative role of renunciation in the history of Hinduism; (2) the Indian caste system as a hierarchy regulated according to ritual purity and the alternative model by A. M. Hocart of the Indian society as a ritual organization; and (3) theoretical discussions regarding the need to go beyond the purity-impurity dichotomy and integrate another opposition, that between the auspicious and the inauspicious, in order to develop a more precise analytical tool in the research of Hindu culture.

DANSK RESUME: Denne korte artikel diskuterer to vigtige bidrag af den franske sociolog Louis Dumont, hans essay "World Renunciation in Indian Religions" og hans hovedværk om det indiske kastesystem, Homo Hierarchicus. Noget af den kritik, der blev rejst mod Dumonts ideer om verdensforsagelse, hierarki og renhed, diskuteres med særlig fokus på tre punkter: (1) Verdensforsagelsens kreative betydning for hinduismens udvikling; (2) Dumonts model af det indiske kastesystem som et hierarki reguleret $i$ forhold til rituel renhed og A. M. Hocarts alternative model, der ser hindusamfundet som en rituel organisation koncentrisk centreret omkring kongen; (3) de teoretiske diskussioner om nødvendigheden af at supplere rent-urent dikotomien med endnu en dikotomi, nemlig mellem det lykke- og ildevarslende, for at udvikle et mere præcist analyseapparat $i$ udforskningen af hinduismen.

KEYWORDS: Louis Dumont; Caste; Renunciation; Hinduism; Pure-Impure Dichotomy; Auspicious-Inauspicious Dichotomy; Arthur Maurice Hocart; Frédérique Apffel Marglin 
Louis Dumont (1911-1998) blev mest kendt som forfatter til en sammenhængende teori om det indiske kastesystem, som han formulerede i sin bog Homo Hierarchicus (Dumont 1980) udgivet først på fransk i 1966. I kraft af den blev han også den samlende figur i en ny indisk sociologi. Sammen med David Pocock etablerede han tidsskriftet Contributions to Indian Sociology, der i sit første nummer (1957) introducerede sig selv med Dumonts essay "For a Sociology of India". Heri hedder det, at "a sociology of India lies at the point of confluence of Sociology and Indology" (Madan 1982, 409-410). Frem for blot at observere det indiske samfunds institutioner på lokalt niveau, hævder denne nye holistiske indienssociologi, at udgangspunktet må være en forståelse af den idéhistorie, som den indiske civilisation bygger på. Dumont søgte derfor indsigt i den klassiske indiske sanskritlitteratur og uddrog af den den totalitet af ideer, der måtte være den strukturelle ramme for forståelsen af det indiske samfund. Ifølge Madan (ibid, 409) havde Dumont faktisk studeret sanskrit (hvor meget og hvor gør han os ikke klogere på). Det, Dumont siden blev kritiseret for, var især, at denne klassiske sanskritlitteratur er produceret af en lille præstelig klasse, der egentlig blot har søgt at optimere sine egne vilkår gennem denne litteratur (primært lovlitteraturen, som også var den, Dumont trak mest på). Sanskritlitteraturen kan derfor umuligt give et fair billede af den mangfoldighed og flertydighed af ideer, værdier og normer, der gennemsyrede livet i de indiske samfund. Alene mangfoldigheden af kollektive identiteter fordelt på etniske, økonomiske, sproglige og erhvervsmæssige skel i et så stort land som Indien burde udgøre et blinkende advarselssignal fra starten af dette nye projekt.

Dumonts skrevne produktion er stor og perspektiverne er mange. Tilsvarende for kritikken af den. I det følgende vil jeg blot trække enkelte punkter frem, der har haft betydning for mit eget arbejde med at forstå den lovlitteratur, Dumont opfattede som parameter for en total forståelse af 'det indiske samfund'. Jeg vil trække tre problemstillinger frem. 1) Dumonts idé om en strukturelt styrende modsætning i indisk tænkning mellem 'the renouncer' og 'the man in the world" $i$ hans essay "World Renunciation in Indian Religions" (Dumont 1980 [1960]); 2) Dumonts fremstilling af det indiske kastesystem som baseret på et hierarki styret af begreberne om rent og urent, mest sammenhængende formuleret i Homo Hierarchicus; i denne sammenhæng præsenterer jeg nogle af kritikpunkterne, der er rejst mod denne fremstilling, en kritik der især bygger på Arthur M. Hocarts alternative forståelse af kastesystemet (Hocart 1950), som derfor vil blive omtalt nærmere; og 3) en original kritik af Dumonts brug af modsætningen mellem rent og urent der hævder, at denne dikotomi ikke kan stå alene, men må inddrage endnu én, nemlig forholdet mellem det lykke- og ildevarslende (Marglin 1985; Carman og Marglin 1985).

\section{Verdensforsageren og manden i verden}

Jeg blev anbefalet af min vejleder, Erik Sand, at læse Dumonts essay om verdensforsagelsen og manden i verden, da jeg skrev originalsprogsopgave i 1989 om Bhagavadgītā. For en umiddelbar læsning er Bhagavadgītā noget værre rod af modsatrettede 
religiøse ideer: social pligtopfyldelse i familien og kasten, vedisk offer, upanishadisk ātman-lære om et udødeligt Selv, der uafhængigt af kroppens dødelighed vandrer fra inkarnation til inkarnation, sāṃkhya-filosofi om åndens totale isolation fra stoffet, yogisk forsagelse af sansepåvirkninger i afsondret meditation, og teistisk hengivenhed til Kṛșna og herligheden ved at indgå i ham, mens man udfører alle de pligter, som kasten kræver af én. Dumonts essay fik i det mindste sat en struktur for læsningen. Fundamentalt for Bhagavadgītā er ganske rigtigt et modsætningsforhold mellem handling i verden og forsagelse af handling, der var bygget op igennem de foregående århundreders indiske religionshistorie. Modsætning bunder i et sociologisk modsætningsforhold mellem 'samfundet' bestående af adskilte klasser (varna) og kaster $(j \bar{a} t i)$ og grupper af asketer uden for dette samfund, sådan som disse relationer udviklede sig i slutningen af den vediske periode fra omkring 500 f.v.t. I sin familie, klasse og kaste var mennesket ifølge Dumont en blot og bar social relation, ikke et individ med valgmuligheder. Individualitet kunne kun realiseres uden for samfundet, og det er grunden til, at der ved siden af dette opstod modsamfund, grupper af verdensforsagere ("renouncers"), for hvem eksistens i 'verden' (dvs. samfundet) forekom at være en ren illusion, og forløsning fra den en frelse.

Dumont selv siger det skarpere:

To say that the world of caste is a world of relations is to say that the particular caste and the particular man have no substance: they exist empirically, but they have no reality in thought, no Being. [...] I regard it as fundamental and would therefore firmly posit, at the risk of being crude, that on the level of life in the world the individual is not (Dumont 1980, 272).

Det er jo et stærkt udsagn, og kritikken af tankegangen i efterfølgende poststrukturalistiske kvinde- og subaltern-studier så det som en blind underkendelse af almindelige menneskers agency igennem historien. Men denne agency kan heller ikke læses ud fra de sanskrittekster, Dumont henholder sig til. Både kvinde- og subaltern-studierne trækker i stedet på tekster på regionale sprog, mundtligt overleverede fortællinger og etnografisk feltarbejde.

Det var ifølge Dumont således selve den brahminske samfundsmodel, der var forudsætningen for fremvæksten af alle de mere eller mindre antibrahminske forsagelsesbevægelser. De to grupperinger indgik i en symbiose. Forsagerne var i kraft af deres særlige frihed (beskyttet af samfundet) i stand til at producere nytænkning og nyvurdering. Det var fra dem, mener Dumont $(1980,276)$, initiativet udgik til den formidable idéhistoriske udvikling, der spænder fra de ældste upanishader (omkring 6-500 f.v.t.) til bhakti-sekterne i middelalderen.

Den skarpe adskillelse mellem forsagerne, der søgte efter en indsigt uden for samfundet, men støttedes af lægfolk, hos hvem de kunne tigge mad, og så disse lægfolk, der måtte arbejde for føden til sig selv og de asketiske tiggere, havde videre konsekvenser:

This allows society, in relegating the temporal to a subordinate position, and in contradistinction to simpler societies, to found itself directly upon the absolute order (Dumont 1980, 278). 
Med andre ord, adskillelsen mellem religiøs fordybelse blandt forsagere og materiel produktion hos lægfolk understøtter et hierarki, der hævdes at udgå fra skabelsens absolutte orden med præsteklassen i toppen af pyramiden og de producerende klasser i bunden. Det er en af grundene til at præsteklassen siden fremkomsten af de asketiske bevægelser inkorporerede verdensforsagernes idealer i deres selviscenesættelse, men på en sådan måde at de samme idealer i praksis uskadeliggjordes - den såkaldte, typiske brahminske inklusivisme (se Oberhammer 1983). Askettilværelsen, der i forsagelsesbevægelserne skulle tiltrække unge, energiske mænd fra gode familier, relegeredes i den brahminske version af det ideelle livs fire livsstadier (elev, familieforsørger, eneboer og asket) til at være en alderdomssyssel, der henlægges til en periode, hvor alle pligter i forhold til familie og kaste er opfyldt (Olivelle 1993, 136-139). Som sådan letter askettilværelsen også familien fra ansvaret for den gamle, som her må overlade styringen til den ældste søn og selv forsage alt (først og fremmest offerilden) og forlade hjemmet for at begive sig ud i ensomheden som munk i sin søgen efter mokșa - ifølge den ideelle model (ibid, 120-122).

Inklusivismen, der inkorporerer og tæmmer forsagelsens idealer, gennemsyrer Bhagavadgītā, der mest af alt er en relegitimering og rekonsolidering af den brahminske samfundsmodels pligtopfyldelse i de fire klasser efter århundreder med buddhistisk succes og begunstigelse hos herskerne. Med Dumonts ord: "at the risk of being crude", vil jeg derfor påstå, at frem for at være et udtryk for et forsagelsesideal er det centrale udsagn i Bhagavadgìtā snarere dette:

Bedre er det at udføre sin egen pligt ufuldstændigt, end at udføre en andens pligt godt. Når man udfører en handling, der er bestemt af ens natur, pådrager man sig ikke skyld. Man bør ikke, oh Arjuna, undlade at udføre sin medfødte pligt, selv hvis den er besmittet med fejl, for alle foretagender er omgivet af fejl, ligesom ilden af røg (BhG 18.47-48 i Sand og Andreasen 2011, 44).

Ifølge den præstelige samfundslære som den kom til udtryk i lovlitteraturen udspringer klassernes pligter af den natur, Skaberen har nedlagt i dem (se fx Manus Lovbog 1.28-31 i Andreasen og Aktor, 2008, 11). En kriger skal ikke påtage sig en askets idealer, men følge sin natur og dræbe fjenderne. Derved beskytter han præsteklassen, hvis natur fra Skaberens side er ikke-vold. Verdensforsagelsen er tæmmet; Bhagavadgītās nytænkning udgår ikke fra en forsagerideologi, men fra en præstelig omfortolkning af denne, der har indoptaget bhakti-religiøsitetens nye universalistiske tanker om en guddommelig-menneskelig verdensfrelser som legitimering af sit budskab om familie- og kastepligt.

Det stærke fokus på forsagerideologien hos Dumont affødte også kritik i form af studier, der søgte at dokumentere betydningen af lægmandsideologien for udviklingen af hinduismen. T. N. Madan forsøgte at korrigere Dumont:

Though he may be tall and splendid, the renouncer is by no means the only actor on the Hindu stage of life. In fact he is not on the stage at all, having left it, but looks at it from the sidelines, as It were. The figure in the centre of the stage is a rather homely character, namely, the householder (grhastha). If not exactly cast in a heroic mould, he is not the 'phantomlike' man either that Dumont considers him to be (Madan 1987, 2). 
Det, Madan kritiserer, er ikke ideen om, at forholdet mellem verdensforsagerens og familiemandens ideal kom til at udgøre en vigtig gennemgående modsætning i indisk religionshistorie, men blot den måde Dumont undervurderer de familieforsørgende klassers muligheder for at præge samfundet og religionen. Kulten i templet og i hjemmet for én eller flere udvalgte guddomme udgik fra dette lags religiøse behov og fik en helt dominerende betydning for hinduismens udvikling op gennem middelalderen og stadig i dag.

Andre kritiserer Dumonts fremstilling for at være både for simpel og for idealtypisk. Patrick Olivelle skriver:

Indeed, Dumont's structural dichotomy between the renouncer and the man in the world is tenable only at the level of ideal types: the lived reality of both the ascetics and people living in society was much more complex and much less tidy. The more significant point of Dumont's analysis, in my view, is the dialectical and creative relationship and tension in which the ascetic and the societal dimensions of Indian religions existed and developed both ideologically and in their institutions and practices (Olivelle 1995, 188). ${ }^{1}$

\section{Kastesystemet, hierarki eller centralitet?}

Dumonts værk Homo Hierarchicus udkom på fransk i 1966. Mary Douglas skrev forord til den engelske udgave fra 1972. Her (Douglas 1975, 185-187) opsummerede hun Dumonts teori i fire punkter:

1. det fundamentale træk ved det indiske samfund er adskillelsen mellem status og magt $^{2}$

2. status er bestemt i forhold til en religiøs ideologis overordnede totalitet

3. dikotomien mellem rent og urent adskiller det sociale fra det organiske

4. denne dikotomi udgør paradigmet for det differentierede hierarki, vi kender som kastesystemet.

Hos Dumont er det indiske sociale system orienteret top-down fra Brahminen til den Urørlige. ${ }^{3}$ Samfundet er basalt struktureret fra helheden til delene, dvs. fra struktur

1 Jeg vil i øvrigt anbefale denne artikel af Patric Olivelle, der er bygget op som en serie af modstillinger af uddrag fra tekster fra henholdsvis verdensforsagere og verdensbekræftere, som noget af det bedste, der er skrevet om indisk askese.

2 Edmund Leach (1971: 235) var skeptisk over for denne påstand og kritiserede i det hele taget Dumonts model for at være formalistisk og for at have begrænset relevans i forhold til en forståelse af det samtidige kastesamfund.

3 Det samfund, der er tale om, er summen af grupper inddelt i fire klasser (varna) og utallige kaster (jäti). De fire klasser er præsteklassen (brāhmaṇa, brahminerne), kriger- og herskerklassen (kșatriya), jordejer- og handelsklassen (vaiśya) og håndværker-, arbejder- og tjenerklassen (śūdra). Under disse fire, men forstået som opstået ved blanding af de fire klasser, rangerede en gruppe af såkaldt urørlige kaster, der primært udgjorde en ufaglært arbejdskraft og i øvrigt beskæftiget i erhverv forbundet med biologisk og moralsk urenhed, $\mathrm{fx}$ som kremeringsarbejdere, garvere, skomagere, fangevogtere og bødler. For oversigt og uddybning, se Aktor 2018a. Den måske væsentligste kritik af Dumonts 
til substans. Status defineres i forhold til en ideologi (helheden) og er derfor hierarkisk over magten (substans). For Dumont betød det, at de brahminske værdier (ideologien) udgør de parametre, i forhold til hvilke alt andet er defineret (Dumont 1980: 3642). De brahminske værdier udledte Dumont primært fra klassiske sanskrittekster med særlig fokus på lovlitteraturen (dharmaśāstra), f.eks. Manus Lovbog. Men Dumonts læsning af disse tekster er ikke dybgående. Teksternes ærinde er primært at sikre præsteklassen en alliance med herskerne som en rekonsolidering af de præstelige værdier efter et par århundreders buddhistisk dominans. Læren om de fire klasser med brahminerne og herskerne i toppen er et middel til dette. Patrick Olivelle skriver:

It is clear that the varna system was not an objective and disinterested classification of ancient Indian society. It was from the start an ideologically driven enterprise designed to place the Brāhmaṇa at the top of a pyramidal social hierarchy, supporting the claim to power of the Kșatriya class and in a special way reducing the Śüdras and other lower classes to a marginal and oppressed status (Olivelle 2018, 18).

Dumont har ikke øje for denne pragmatiske og historiske kontekst og forsøger ikke at nå bag om teksternes retoriske strategier $\mathrm{fx}$ ved at inddrage kommentarlitteraturen. Han diskuterer heller ikke spørgsmålet om, i hvilken grad disse teksters ideale samfundsmodel havde nogen empirisk realitet. Inddrager man andre kilder, vil man se, at den præstelige model, kendt fra lovbøgerne, ikke eller kun i udvandet form genfindes i disse. I Aśokas edikter (han regerede fra 269 til 232 f.v.t.) er kun navnet for præsteklassen nævnt (brähmana), og det som et religiøst samfund ved siden af andre, ikke som en klasse i et socialt hierarki. Navnene på de tre andre klasser mangler helt såvel som betegnelsen for 'klasse", varna; i den klassiske grammatiske litteratur mangler f.eks. et ord som dvija, 'to-gange-født' (dvs. indviet til læretidens vedarecitation), der var et vigtigt marginaliserende begreb i lovlitteraturen ved at rangere de tre øverste klasser over den fjerde, śüdraerne, der kun var 'en-gang-født' (dvs. ikke indviet til recitation og brug af de fire vedaer). Selv den klassiske politiske tekst, Arthaśāstra, en manual for herskeren, afviger fra den brahminske model: brahminerne prises ikke særskilt, som de bliver i lovbøgerne, og śüdraerne anerkendes som håndværkere i modstrid med opfattelsen i Manus Lovbog, hvor de kun omtales som tjenere; endelig viser et studie af førkoloniale donationsindskrifter, at donorer sjældent identificerede sig ved betegnelsen på en klasse eller kaste bort set fra medlemmer af præsteklassen (Aktor 2018a, 64). Disse og andre kilder sætter Dumonts ensidige brug af den brahminske lovlitteratur i et kritisk lys.

Korrelationen mellem grader af rituel renhed og placering i hierarkiet bestående af fire klasser er en abstraktion, der ikke genfindes i sanskritteksterne. De omtaler ofte brahminerne som særligt fortrinlige, men sjældent med ord som 'ren"; tilsvarende er det sjældent at se formuleringer, der direkte omtaler lavkasterne som 'urene' (Olivelle 1998).

model er, at den tager udgangspunkt i denne ideelle struktur, sådan som den er præsenteret i klassiske tekster, hvilket gør den problematisk at anvende i en analyse af den langt mere forskelligartede sociale virkelighed. 
Korrelationen er heller ikke logisk stringent. For hvis rituel renhed var det styrende princip, burde krigerklassen være placeret i bunden, under jordejer- og håndværkerklasserne, ikke som i teksterne som nummer to under brahminerne. Krigere og prinser lever rituelt set et urent liv med drab, vold, kødspisning, alkohol og sex. Dumont var selv opmærksom på dette problem (1980, 77). I sin løsning på problemet forlader han det strukturelle og idealtypiske princip og forfalder til ren pragmatisme: "[Power] exists in the society, and the Brahman who thinks in terms of hierarchy knows this perfectly well" (ibid). Brahminerne er nødt til at bryde princippet om rituel renhed og placere krigerne på andenpladsen, med mindre de helt ville benægte deres værdighed og funktion i samfundet. På det grundlag udvikler han begrebet om den omsluttede magt:

As the mantle of Our Lady of Mercy shelters sinners of every kind in its voluminous folds, so the hierarchy of purity cloaks, among other differences, its own contrary. Here we have an example of complementarity between that which encompasses and that which is encompassed (ibid, 78).

I kritikken af Dumont fremkom andre løsninger på dette problem, der forekommer rigtigere. Nu vil jeg først behandle det forslag, der bygger på analysen af den engelske etnograf Arthur M. Hocart. To af de vigtigste kritikere af Dumonts model, Gloria Goodwin Raheja (1988) og Declan Quigley (1993), byggede begge deres kritik på Hocarts alternative model, der frem for hierarki lægger vægt på centralitet. I modsætning til Dumont, der så samfundet som struktureret fra en hierarkisk top, opfattede Hocart det som organiseret omkring magtcentre. Hocarts grundlæggende idé er at se hindustaten som en rituel organisation, der inkluderede de fire klasser og de mange kaster. Betegnelserne for disse kaster i lovbøgerne er primært betegnelser for rituelle serviceydelser. 'Trommeslagere' ernærede sig næppe af trommespil ved bryllupper og kremeringer alene men som landarbejdere og daglejere; men de kendes som trommeslagere, fordi denne aktivitet indgår i de ritualer, som ritualets 'offerherre' har brug for. Det er kongen, der er den paradigmatiske offerherre (yajamāna) og dermed den centrale figur i hele denne organisation. Men systemet er multicentreret og rækker ned i samfundet såvel som op i himlen:

The King's state is reproduced in miniature by his vassals: a farmer has his court, consisting of the personages most essential to the ritual and so present even in the smallest community, the barber, the washerman, the drummer and so forth. [...] The temple and the palace are indistinguishable, for the king represents the gods. [...] The god in his temple has his court like the king in his palace: smiths, carpenters, potters, all work for him (Hocart 1950, 68).

Centralitetsmodellen forekommer at afspejle det førkoloniale hindusamfund bedre, især forholdet mellem brahminer og konger. Brahminerne kunne individuelt selv fungere som offerherre, men til syvende og sidst var de afhængige af, at mænd fra de andre klasser hyrede dem til religiøse tjenester. Både i forhold til kongen og i forhold til andre, der hyrede dem som præster, var og blev de en serviceklasse. 


\section{Ren eller lykkevarslende?}

En anden og mere sofistikeret løsning på problemet med de urene krigere på andenpladsen i hierarkiet kom primært fra den franske antropolog Frédérique Marglins arbejde med at inddrage dikotomien lykke- og ildevarslende som et supplement til modsætningen mellem rent og urent. Andre før hende havde være optaget af vigtigheden af denne anden dikotomi, men havde været mere tilbøjelig til at se den som en parallel snarere end som en supplerende anden akse i forhold til rent og urent. Først i strømmen af kritik af Dumont blev det aktuelt at fremhæve denne anden akse. Sammen med John Carman udgav Marglin en antologi, hvor forskellige forskere belyste hvilken indflydelse ideer om det lykke- og ildevarslende har i forhold til et givent materiale (Carman \& Marglin, 1985).

T. N. Madans bidrag til antologien undersøger, hvordan ord for det lykkevarslende (śubha, mangala) og det rene (śuddha) bliver brugt i hverdagssproget. Han konkluderer, at ordene for det lykke- og ildevarslende især bruges i forbindelse med tid og begivenheder såsom religiøse fester, astrologiske konstellationer og livcyklusritualer, hvorimod ordene for rent og urent typisk indgår i sammenhænge, der drejer sig om tilstande $f x$ vedrørende føde og forskellige materialer.

Marglin (1985, 138-142, 289-291) ser en parallel mellem kongen og hustruen, der begge er kilder til (og ansvarlige for) velstand, frugtbarhed og forøgelse, altså resultater af de lykkevarslende kosmiske kræfter. De er også klart forbundet med tid, hustruen til familiens livscyklusritualer, kongen til de astrologiske forhold, der er bestemmende for hans handlinger. Begge er også forbundet med urenhed, hustruen gennem menstruation og fødsel, kongen gennem vold, kød, alkohol og sex. Hun foreslår derfor, at det kun er muligt at forklare deres placering - hustruen som hjemmets gudinde, men også uren, kongen som nummer to i det brahminske hierarki skønt voldelig osv. - ved at inddrage deres betydning og værdi på aksen af det lykkeog ildevarslende.

Man kan måske systematisere relationen mellem de to forskellige akser. Hvis vi tager udgangspunkt i Hocarts forståelse af hindusamfundet som en rituel organisation, kan man forbinde aksen med rent og urent til menneskelig aktivitet, og aksen med det lykke- og ildevarslende til kosmisk og guddommelig aktivitet; ritualet er et samspil af disse to typer aktivitet. Idet rækkevidden af menneskelig aktivitet er begrænset, må den gennem ritualer aktivere guddommelig aktivitet, men netop fordi mennesker ikke er guder, kan resultatet kun sikres ved at stille særlige krav til de mennesker, der skal udføre de rituelle handlinger. Disse krav udtrykkes typisk i et renhedsidiom: Idet menneskets kropslige behov opfattes som det, der klarest adskiller mennesker fra guder, integreres 'renselse' i form af observanser, der suspenderer kropslige aktiviteter som sex, fødeindtagelse, søvn osv., som forudsætning for det vellykkede ritual. Renhed bliver derved en vigtig menneskelig forudsætning (en felicity condition med et talehandlingsteoretisk begreb) for den guddommelige aktivitets lykkelige resultater. 
Et eksempel på anvendeligheden af denne ekstra akse, det lykke- og ildevarslende, i samspil med rent og urent har vi i forhold til en kompliceret lovtekst, om hvad der skal ske med en højkastehustru, der har haft et illegitimt seksuelt forhold til en person fra en urørlig lavkaste. Teksten er fra en stor kommentar fra midten af det fjortende århundrede over en lovtekst, Parāśarasmṛti, fra omkring sjette århundrede. Tekst og kommentar til sammen opstiller følgende fem muligheder: ${ }^{4}$

1. Kvinden er i forvejen gravid med sin højkaste-ægtemand, og samlejet med den urørlige var ikke tilsigtet: Kvinden afsondres fra resten af familien, mens hun er gravid, men skal ikke udføre nogen bodsøvelse i denne periode; først efter barnet er født, skal hun faste delvist i tolv dage.

2. Hun er ikke gravid i forvejen, og samlejet med den urørlige blev afbrudt: Kvinden skal gennemføre en hård, men delvis faste igennem en måned.

3. Kvinden er ikke gravid i forvejen; samlejet med den urørlige blev gennemført, men var utilsigtet, og hun bliver ikke gravid: Kvinden skal igennem et hårdt (og farligt) bodsritual, hvor hun skal stå opret i et hul fyldt med komøg i et døgn; derefter skal hun faste nogle dage og atter tilbage i hullet i et døgn, denne gang fyldt med vand, for endelig at slutte af med yderligere faste, ind til hun får sin næste menstruation.

4. Kvinden er ikke gravid i forvejen; samlejet med den urørlige blev gennemført og var tilsigtet, men hun bliver ikke gravid: Kvinden skal igennem et års bodsritualer (typisk forskellige former for delvis faste).

5. Kvinden er ikke gravid i forvejen med sin ægtemand, men bliver gravid ved samlejet med den urørlige: Kvinden skal ikke udføre nogen form for bodsritual, men skal forvises af sin ægtemand til et andet land.

Udgangspunkt for forståelse af disse situationer er, at en hustrus renhed er knyttet til hendes kompetence, hendes agency, i forhold til reproduktion. Vi ser yderligere, hvordan renhed er knyttet til et menneskeligt plan, hvorimod det lykke- og ildevarslende er knyttet til et kosmisk / guddommeligt plan, der regulerer forhold, mennesker ikke alene kan kontrollere, f.eks. graviditet. Når det gælder børnefødsler, er hustruen en aktør, der skal være ren for at udgøre det perfekte instrument for den kosmiske aktivitet, der alene kan sikre, at hun bliver gravid, og helst med en søn. I den første situation er resultatet af den lykkevarslende kosmiske aktivitet allerede sikret: hustruen er gravid ved sin ægtemand. Renselse er derfor ikke nødvendig i forhold til den lykkelige frugt, barnet, men alene - og først efter barnet er født - med henblik på hustruen som instrument for kommende fødsler. I den sidste situation triumferer den ildevarslende kosmiske aktivitet - kvinden er gravid, men med den forkerte mand, og det endda den laveste af alle, der som erhverv selv er beskæftiget med ildevarslende aktiviteter som kremeringsarbejder, jæger o.l. Renselse er derfor slet ikke mulig

\footnotetext{
4 Originaltekst og analyse i Aktor 2008, 171-179. De fem punkter her er en proportional, men forenklet sammenfatning.
} 
og heller ikke relevant. Kvinden er uhelbredeligt fordærvet, og skal forkastes af ægtemanden og bortvises til et andet land. Men i situationerne mellem disse to yderligheder er den kosmiske aktivitet, lykke- eller ildevarslende, slet ikke involveret, da der ikke er nogen undfangelse. Så det er her i disse mellemliggende situationer, vi ser de mest udførlige renselsesritualer. Disse skal genoprette den renhed, der er nødvendig, hvis hustruen skal gøre sig håb om senere at blive gravid med sin ægtemand.

I øvrigt er det karakteristisk for lovlitteraturen med dens ensidige fokus på renhed, at den ikke skal læses isoleret men i sammenhæng med de astrologiske manualer, der fastsatte regler for lykke- og ildevarslende tidspunkter - i øvrigt ikke sjældent forfattet af de samme personer. Dernæst er 'renhed' i denne litteratur et stærkt differentieret begreb med en tilsvarende differentieret terminologi. Der er jo tale om en præstelig litteratur, så renhed er som nævnt basalt set en forudsætning for et vellykket ritual. At have renset sig [śuddhi] er ifølge definitionen i en middelalderlig afhandling om renselse "at være kvalificeret til at udføre de ritualer, der er kendt fra Vedaerne" (Aktor 2018b, 221). Urenhed klassificeres i forskellige kategorier forbundet med forskellige kategorier af renselse. Snavs ved en persons krop eller ejendele fjernes i overensstemmelse med regler for hygiejne og rengøring (śauca). Urenhed i familielivet, som ved kvinders menstruation og fødsler og ved dødsfald i familien fjernes ved overholdelse af reglerne for dødsurenhed (āśauca), og 'indre' urenhed relateret til tanker, tale og sanser fjernes gennem forskellige mindre bodsøvelser (prāyaścitta). Hver af disse kategorier har hver for sig utallige underkategorier (for detaljer, se Aktor 2018b).

\section{Konklusion}

Louis Dumont var en stor inspiration for Indiensforskningen, både den antropologiske, sociologiske og indologiske - alle tre discipliner, der ganske enkelt var nødt til at forholde sig til hans ideer - hvoraf mange slet ikke er berørt i denne korte artikel. Ved selv at kombinere antropologi, sociologi og indologi skabte han skole for en frugtbar tværfaglig tilgang til de indiske kilder, som har sat sig spor i store dele af indologien lige siden. Han blev på alle måde produktiv. Hans eget værk dannede model og skole for den indiske sociologi i et par årtier, og af den kritik, det genererede fra 1980erne og fremad, opstod et væld af frugtbare indsigter. I den forstand er det fattigt kun at forholde sig til de sider af hans værk, der har haft direkte relevans til mit eget arbejde, men andre har allerede været der for en mere udførlig gennemgang og diskussion ser herfor Stenski 2008.

\section{LITTERATUR}

Aktor, Mikael

2008 Ritualisation and Segregation: The Untouchability Complex in Indian Dharma Literature with Special Reference to Parāśarasmrti and Parāśaramādhavīya, Torino: Corpus Iuris Sanscriticum CESMEO.

2018a "Social Classes - varna", in: Patrick Olivelle \& Donald R. Davis, Jr, eds., Hindu Law: A New History of Dharmaśāstra [i serien The Oxford History of Hinduism], Oxford: Oxford University 
Press, 60-77.

2018b "Impurity and Purification - àśauca, śauca", in: Patrick Olivelle \& Donald R. Davis, Jr, eds. Hindu Law: A New History of Dharmaśāstra [i serien The Oxford History of Hinduism], Oxford: Oxford University Press, 220-235.

Andreasen, Esben \& Mikael Aktor

2008 Manus Lovbog, dddrag ved Esben Andreasen, oversættelse og kommentarer ved Mikael Aktor, Aarhus: Systime.

Carman, John B. \& Frédérique A. Marglin, eds.

1985 Purity and Auspiciousness in Indian Society, Leiden: Brill.

Douglas, Mary

1975 “Louis Dumont's Structural Analysis”, in: idem, Implicit Meanings: Essays in Anthropology, London: Routledge and Kegan Paul, 181-192 [oprindeligt 1972].

Dumont, Louis

1980 Homo Hierarchicus: The Caste System and Its Implications, rev.ed., Chicago: The University of Chicago Press [oprindeligt 1966]. Heri indgår "World Renunciation in Indian Religions" som Appendix B, 267-286, trykt første gang i Contributions to Indian Sociology 4, 1960, 32-62.

Hocart, Arthur M.

1950 Caste: A Comparative Study, London: Methuen.

Leach, Edmund

1971 "Hierarchical Man: Louis Dumont and his Critics", South Asian Review 4, 233-237.

Madan, T. N.

1982 Way of Life - King, Householder, Renouncer: Essays in honour of Louis Dumont, Delhi: Motilal Banarsidass.

Madan, T. N.

1987 Non-Renunciation: Themes and Interpretations of Hindu Culture, Delhi: Oxford University Press.

Marglin, Frédérique Apffel

1985 Wives of the God King: The Rituals of the Devadasis of Puri, Delhi: Oxford University Press.

Oberhammer, Gerhard, ed.

1983 Inklusivismus: eine indische Denkform, Leiden: Brill.

Olivelle, Patrick

1993 The Áśrama System: The History and Hermeneutics of a Religious Institution, New York: Oxford University Press.

1998 "Caste and Purity: A Study in the Language of the Dharma Literature", Contributions to Indian Sociology 32, 190-216. https://doi.org/10.1177/006996679803200203

1995 "Deconstruction of the Body in Indian Asceticism", in: Vincent L. Wimbush \& Richard Valantasis, eds., Asceticism, New York: Oxford University Press, 188-210.

2018 "Social and Literary History of Dharmaśāstra: The Foundational Texts", in: Patrick Olivelle \& Donald R. Davis, Jr, eds., Hindu Law: A New History of Dharmaśāstra [i serien The Oxford History of Hinduism], Oxford: Oxford University Press, 15-29. https://doi.org/10.1093/oso/9780198702603.003.0002

Quigley, Declan

1993 The Interpretation of Caste, Oxford: Oxford University Press.

Raheja, Gloria Goodwin

1988 The Poison in the Gift: Ritual, Prestation, and the Dominant Caste in a North Indian Village, Chicago: University of Chicago Press.

Sand, Erik Reenberg \& Esben Andreasen

2011 Bhagavadgita, uddrag oversat af Erik Reenberg Sand, indledning og efterskrift ved Esben Andreasen, Aarhus: Systime.

Strenski, Ivan

2008 Dumont on Religion: Difference, Comparison, Transgression, Sheffield: Equinox. Genudgivet af 
Routledge i 2014.

Mikael Aktor, lektor, ph.d.

Religionsstudier, Institut for historie, Syddansk Universitet aktor@sdu.dk. 